\title{
Topic Study Group No. 15: Teaching and Learning of Statistics
}

\author{
Dani Ben-Zvi, Gail Burrill, Dave Pratt, Lucia Zapata-Cardona \\ and Andreas Eichler
}

\section{The Programme}

\section{TSG-15 Rationale}

Being able to provide sound evidence-based arguments and critically evaluate data-based claims are important skills that all citizens should have. It is not surprising therefore that the study of statistics at all educational levels is gaining more students and drawing more attention than it has in the past. The study of statistics provides students with tools, ideas and dispositions to use in order to react intelligently to information in the world around them. Reflecting this need to improve students' ability to think statistically, statistical literacy and reasoning are becoming part of the mainstream school and university curriculum in many countries.

As a consequence, statistics education is growing and becoming an exciting field of research and development. Statistics at school level is usually taught in a mathematics classroom in connection with learning probability. To allow for this instructional convention, Topic Study Group 15 (TSG-15) included probabilistic aspects in learning statistics, whereas research with a specific focus on learning probability was discussed in TSG-14 of ICME-13.

Co-chairs: Dani Ben-Zvi, Gail Burrill.

Team members: Dave Pratt, Lucia Zapata-Cardona, Andreas Eichler.

D. Ben-Zvi $(\bowtie)$

The University of Haifa, LINKS I-CORE, Haifa, Israel

e-mail: dbenzvi@univ.haifa.ac.il

G. Burrill

Michigan State University, East Lansing, USA

e-mail: burrill@msu.edu 


\section{TSG-15 Meetings During ICME-13}

The growing interest in statistics education was reflected in the popularity of this group and in the more than 60 papers accepted for presentation. The members of TSG-15 came from 34 different countries and varied significantly by experience, background and seniority. The presentations were divided into six themes related to key issues in statistics education research: core areas in statistics education; technology and the teaching of statistics; statistics education at the elementary level; statistics education at the secondary level; statistics education at the tertiary level; teachers' statistical knowledge and statistics education of pre-service/in-service teachers; and future directions in statistics education.

The four meetings of TSG-15 were organized to create a sense of community among all presenters and participants, who shared a common desire and passion to improve statistics education by focusing on conceptual understanding rather than rote learning. To build and support this sense of community we asked participants to prepare for TSG-15 before they arrived in Hamburg by reading all papers in advance, so we could discuss each other's work; the co-chairs kept informal correspondence with all participants before, during and after the conference; and finally, participants were asked to be involved every day of the program so we could get to know one another, develop collegial networks, welcome our emerging scholars and discuss the important work in statistics education research around the world.

Because of the large number of proposals we received, the time available only allowed for relatively short presentations by the authors. However, we felt it critical that all proposals be given time for presentation in some format. The four meetings were therefore organized to capitalize on community-building and discussions around our collective and individual research. Some of the sessions ran in parallel. In addition there was a poster session dedicated to short poster presentations followed by close viewing and discussions, so that the TSG-15 community could engage more directly with the authors and each other in a relaxed setting. Another highlight of the program was a workshop to reflect as a community on the themes, presentations, issues raised and discussions.

The accepted papers were organized in the following ways:

- 13 poster presentations to promote TSG-15 community discussions with diverse and thought-provoking studies;

- 16 short presentations (10 min talk $+5 \mathrm{~min}$ discussion) in four "Oral Communication Sessions" organized into four themes to enrich understanding of the themes and extend discussions around common interests;

- 23 long presentations and discussions (15 min talk + 5 min discussion) organized in six thematic sessions (two whole group, and two in parallel sessions) to enhance the overarching themes of the short presentation and poster sessions; 
- Short group discussions in almost all sessions to allow for rich interactions and discourse.

TSG-15 had thus nine sessions all together, which were devoted to key issues in statistics education research:

1. Four 90 -min sessions of long papers $(15+5 \mathrm{~min})$, two of which (Sessions 2 and 3) ran in parallel,

2. Four 60 - or 90 -min sessions of short papers $(10+5 \mathrm{~min})$, and

3. One poster session.

\section{TSG-15 Beyond the Conference}

Informal feedback received after the conference was extremely positive. We felt at the end that much can be learned by integrating results from such a variety of research and practice in statistics education. Such integration of theories, empirical evidence and instructional methods can eventually help students to develop their statistical thinking. These ongoing efforts to reform statistics instruction and content have the potential to both make the learning of statistics more engaging and prepare a generation of future citizens that deeply understand the rationale, perspective and key ideas of statistics. These are skills and knowledge that are crucial in the current age of information and big data.

An informal set of proceedings was created to allow for immediate distribution of the TSG-15 papers among those within the TSG-15 members. Before the conference an ICME-13 Topical Survey titled "Empirical research in statistics education" was prepared by team members Andreas Eichler and Lucía Zapata-Cardona (Eichler \& Zapata-Cardona, 2016). This short book (freely available at http://www. springer.com/gp/book/9783319389677) addresses the current state of research in statistics education. It provides a review of recent research into statistics education, with a focus on empirical research published in established educational journals and on the proceedings of important conferences on statistics education. It identifies and addresses six key research topics: teachers' knowledge; teachers' role in statistics education; teacher preparation; students' knowledge; students' role in statistics education; and how students learn statistics with the help of technology. For each topic, the survey builds upon existing reviews, complementing them with the latest research.

A monograph of the best 20 papers presented in TSG-15 is underway. In TSG-12 (ICME-12) a monograph titled "The teaching and learning of statistics: International perspectives" (Vol I, Ben-Zvi \& Makar, 2016) was published. The TSG-15 monograph will be the second volume in this line of publications, and is edited by Burrill and Ben-Zvi (expected publication date: 2016). 


\section{References}

Ben-Zvi, D., \& Makar, K. (Eds.). (2016). The teaching and learning of statistics: International perspectives (Vol. I): Springer International Publishing Switzerland.

Burrill, G., \& Ben-Zvi, D. (in preparation). The teaching and learning of statistics: International perspectives (Vol. II). Springer International Publishing.

Eichler, A., \& Zapata-Cardona, L. (2016). Empirical research in statistics education. An ICME-13 Topical Survey, series editor: Gabriele Kaiser. Springer Open.

Open Access Except where otherwise noted, this chapter is licensed under a Creative Commons Attribution 4.0 International License. To view a copy of this license, visit http://creativecommons. org/licenses/by/4.0/. 